\title{
Evaluasi Sistem Manajemen Informasi Objek Pajak (SISMIOP) Sebagai Sarana Pelayanan Penerimaan Pajak Bumi Dan Bangunan Di Kota Baubau
}

\section{Oleh}

\author{
Ishak Awaluddin $^{1}$, Sulvariany Tamburaka ${ }^{2}$, Widya Ayu Lestari ${ }^{3}$ \\ E-mail: w.ayulestari@gmail.com
}

\begin{abstract}
The research objective is to determine the implementation of the Tax Object Management Information System (SISMIOP) at Baubau city. This study uses primary data and secondary data using the Guttman scale as a measurement scale. The analytical method used in this research is descriptive analysis.

The results showed the implementation of the Tax Object Information Management System (SISMIOP) in the city of Baubau which is a system used by the Financial, Asset and Regional Revenue Management Section of the Land and Building Tax (PBB) sector has been implemented quite well. Can be seen from the system that can accommodate or run the entire existing UN channel process with the support of adequate equipment, competent workforce as well as the compliance and discipline of users.
\end{abstract}

Keywords: Evaluation of the tax object information management system (SISMIOP), PBB

\section{PENDAHULUAN}

Negara Republik Indonesia termasuk dalam Negara Berkembang. Indonesia saat ini banyak melakukan pembangunan di segala bidang seperti bidang hukum, politik, pendidikan, ekonomi serta bidang-bidang lainnya yang memiliki tujuan untuk meningkatkan kesejahteraan masyarakat.Pembangunan di setiap negara memerlukan biaya yang besar, oleh karena itu sumber biaya yang bisa diharapkan mengalami peningkatan salah satunya dapat berasal dari pajak.

Berdasarkan undang-undang nomor 28 tahun 2009. Pajak Daerah adalah kontribusi wajib kepada daerah yang terutang oleh orang pribadi atau badan yang bersifat memaksa berdasarkan undang-undang dengan tidak mendapatkan imbalan secara langsung dan digunakan untuk keperluan daerah bagi sebesar-besarnya kemakmuran rakyat. Sebelum tahun 2014 pajak bumi dan bangunan termasuk dalam jenis pajak pusat, akan tetapi berdasarkan Undang-Undang Nomor 28 Tahun 2009, pajak bumi dan bangunan pedesaan dan perkotaan telah diserahkan kepada kota/kabupaten. (Mardiasmo : 2018)

Banyaknya terjadi ketidak akuratan data seperti pada kesalahan nama wajib pajak maupun luas dan letak objek pajak, banyak pula wajib pajak yang merasa nilai jual objek pajak (NJOP) tidak sesuai sehingga mereka menuntut pengurangan serta rendahnya kesadaran wajib pajak sehingga menyebabkan penangihan PBB tidak berjalan maksimal. Berdasarkan hal tersebut maka pemerintah dalam hal ini Menteri Keuangan dan Dirtjen Pajak melakukan kebijakan dengan menerapkan sistem administrasi perpajakan modern PBB yaitu dengan menggunanakan sistem manajemen informasi objek pajak (SISMIOP).

Pajak di kota Baubau terdiri dari pajak pendapatan Daerah, pajak perusahaan dan pajak bumi dan bangunan. Pajak mempunyai peranan yang sangat penting karena pajak merupakan sumber pendapatan untuk membiayai semua pengeluaran termaksud pengeluaran pembangunan. Sekalipun PBB adalah pajak Negara yang diatur oleh UU Nomor 12 tahun 1994, namun 
wewenang pemungutannya diserahkan ke Walikota Baubau dan hasilnya sebagian besar masuk ke kas Daerah Kota Baubau.

Sebelum menggunakan SISMIOP untuk mengelola data wajib Pajak Bumi dan Bangunan masih secara manual, menurut KPP pratama Kota Baubau sebelum adanya SISMIOP ketetapan SPPT dikelola secara manual. Untuk PBBnya PEMDA ambil alih pada tahun 2013 berdasarkan perda 27 Thn 2013 tentang PBB dan dijalankan Sistem Manajemen Informasi Objek Pajak pada Tahnun 2014. Berbagai upaya dalam meningkatkan kesadaran masyarakat atau wajib pajak telah dilaksanan akan tetapi masih banyak di temukan wajib pajak yang tidak melakukan kewajiban perpajakan dengan benar dan tepat waktu. Dengan subtansi yang dikembangkan terbatas pada penerapan system manajemen informasi objek pajak SISMIOP sebagai praktik reformasi administrasi perpajakan modern diharapkan maka akan meningkatkan pelayanan menjadi lebih baik mulai dari pendataan sampai dengan pelayanan satu tempat.

\subsection{Konsep Dasar Evaluasi}

\section{KAJIAN PUSTAKA}

Evaluasi menurut Stufflebeam dan Shinkfied (1985:159) merupakan suatu proses menyediakan informasi yang dapat dijadikan sebagai perimbangan untuk menentukan harga dan jasa (the worth and merit) tujuan yang di capai, desain, implementasi dan dampak untuk membantu membuat keputusan, membantu pertanggung jawaban dan meningkatkan pemahaman terhadap fenomena. Menurut rumusan tersebut ini dari evaluasi adalah penyediaan informasi yang dapat dijadikan sebagai bahan pertimbangan dalam mengambil keputusan.

\subsection{Tujuan Evaluasi}

Subiyanto (1988: 16) menyatakan bahwa tujuan diadakanya suatu evaluasi adalah untuk mengetahui apakah suatu pengajaran atau program pengajaran efektif atau tidak. Dengan melaksanakn evaluasi orang dapat mengetahui apakah tujuan pengajaran (khususnya tujuan intruksional khusus) dapat tercapai atau tidak.

\subsection{Dasar Hukum dan Pengertian PBB}

Sebelum berlakunya Undang-Undang Nomor 28 Tahun 2009,Pajak Bumi dan Bangunan adalah pajak yang dipungut dan diadministrasikan oleh pemerintah pusat,dan hasil pungutannya diberikan/dibagihasilkan kepada pemerintah daerah(Departemen Keuangan,2009). Pada UndangUndang Pajak Bumi dan Bangunan UU No.12 Tahun 1985, pemerintahan daerah akan menerima penerimaan PBB sebesar 90\% yangakan dibagi kepada pemerintah provinsi dan kabupaten/kota

\subsection{Peralihan PBB dari Pemerintah Pusat ke Pemerintah Daerah}

U 28/2009 adalah dialihkannya Bea Perolehan Ha katas Tanah dan Bangunan (BPHTB) dan pajak Bumi dan Bangunan menjadi pajak daerah. Pada awalnya PBB merupakan paajak yang proses administrasi dilakukan oleh pemerintah pusat sedangkan seluruh penerimaannya dibagikan ke daerah dengan proporsi tertentu. Namun, guna meningkatkan akuntabilitas pengelolaan keuangan daerah, khususnya dari penerimaan $\mathrm{PBB}$, maka paling lambat tanggal 1 Januari 2014 seluruh proses pengelolaan PBB akan dilakukan oleh pemerintah Daerah. Sedangkan PBB sector Perkebunana, perhutanan, dan pertambangan masih tetap menjadi pusat.

\subsection{Tarif dan Dasar Perhitungan}

NJKP ditetapkan serendah-rendahnya $20 \%$ dan setinggi-tingginya $100 \%$ dari NJOP. NJKP ditetapkan dengan peraturan pemerintah No.25 Tahun 2002 tentang besarnya presentase NJKP pada PBB adalah:

1. OP dengan nilai 1 milyar/lebih $=40 \%$ dari NJOP

2. OP perkebunan, Perhutanan, dan Pertambangan $20 \%$ dari NJOP

3. OP lainnya NJKP $20 \%$ dari NJOP

\subsection{Sistem Manajemen Informasi Objek Pajak (SISMIOP)}


Pengertian Sistem Manajemen Informasi Objek Pajak:

a. Sistem adalah sekelompok dari dua atau lebih komponen atau subsistem yang saling berhubungan yang berfungsi dengan tujuan yang sama.

b. Manajemen adalah pencapaian tujuan yang ditetapkan terlebih dahulu dengan mempergunakan sumber-sumber yang tersedia.

c. Informasi adalah data yang telah diolah menjadi bentuk yang memiliki arti bagi si penerima dan bermanfaat bagi pengambilan keputusan saat ini atau mendatang.

Berdasarkan penjelasan diatas dapat ditarik kesimpulan bahwa pengertian SISMIOP adalah sistem yang terintegrasi untuk mengolah institusi data objek dan subyek PBB dengan bantuan computer dimulai dari pengumpulan data, pemberian nomor identitas obyek pajak (NOP) perekaman data, pemeliharaan basis data, pencetakan hasil keluaran, pemantauan penerimaan, pelaksanaan penagihan dan pelayanan.

\subsection{Unsur-unsur Pokok SISMIOP}

1. NOP ( Nomor Objek Pajak)

2. Blok

3. Zona Nilai Tanah (ZNT)

4. Daftar Biaya Komponen Bangunan

5. Program Komputer

\subsection{Tahapan Pelaksanaan SISMIOP}
a. Pendaftaran
b. Pendataan
c. Peniaian

\subsection{Pemeliharaan Basis Data}

Pemeliharaan basis data dilaksanakan atas basis data yang telah dibentuk karena adanya perubahan. Hal ini dilaksanakan agar data yang da di file komputer tatap up to date. Pemeliharaan basis data merupakan bagian dari pelayanan kepada WP, dengan memberikan pelayanan yang baik dan cepat dapat memberikan kepercayaan kepada WP, sehingga dapat melunasi PBB ke tempat pembayaran yang telah ditentukan. pemeliharaan basis data dilaksanakan dengan cara:

1. Pemeliharaan basis data secara pasif

2. Pemeliharan basis data secara kolektif

3. Pemeliharaan basis data secara aktif

4. Pemeliharaan basis data untuk penyempurnaan ZNT dan NIR

5. Pemeliharaan basis data objek dan subjek pajak

\subsection{Hasil Keluaran /produksi SISMIOP}

Hasil keluaran SISMIOP adalah kebutuhan yang diperlukan dalam pengelolaan PBB antara lain :

a. Produksi massal SPPT setiap awal tahun

b. Cetak SPPT hasil pembetulan, keberatan, dan pengurangan.

c. Cetak DHKP (Daftar Himpunan Ketetapan Pajak) per desa

d. Cetak STTS (Surat Tanda Terima Setoran)

e. Cetak SK kakanwil tentang klasifikasi NJOP

f. Melihat peta Blok, peta ZNT

g. Cetak daftar tunggakan

h. Cetak surat teguran/peringatan kepada wajib pajak

i. Dan lain-lain yang menyangkut penagihan dan penerimaan PBB

\subsection{Kerangka Pikir}




\section{Skema 2.1 Kerangka Pikir}

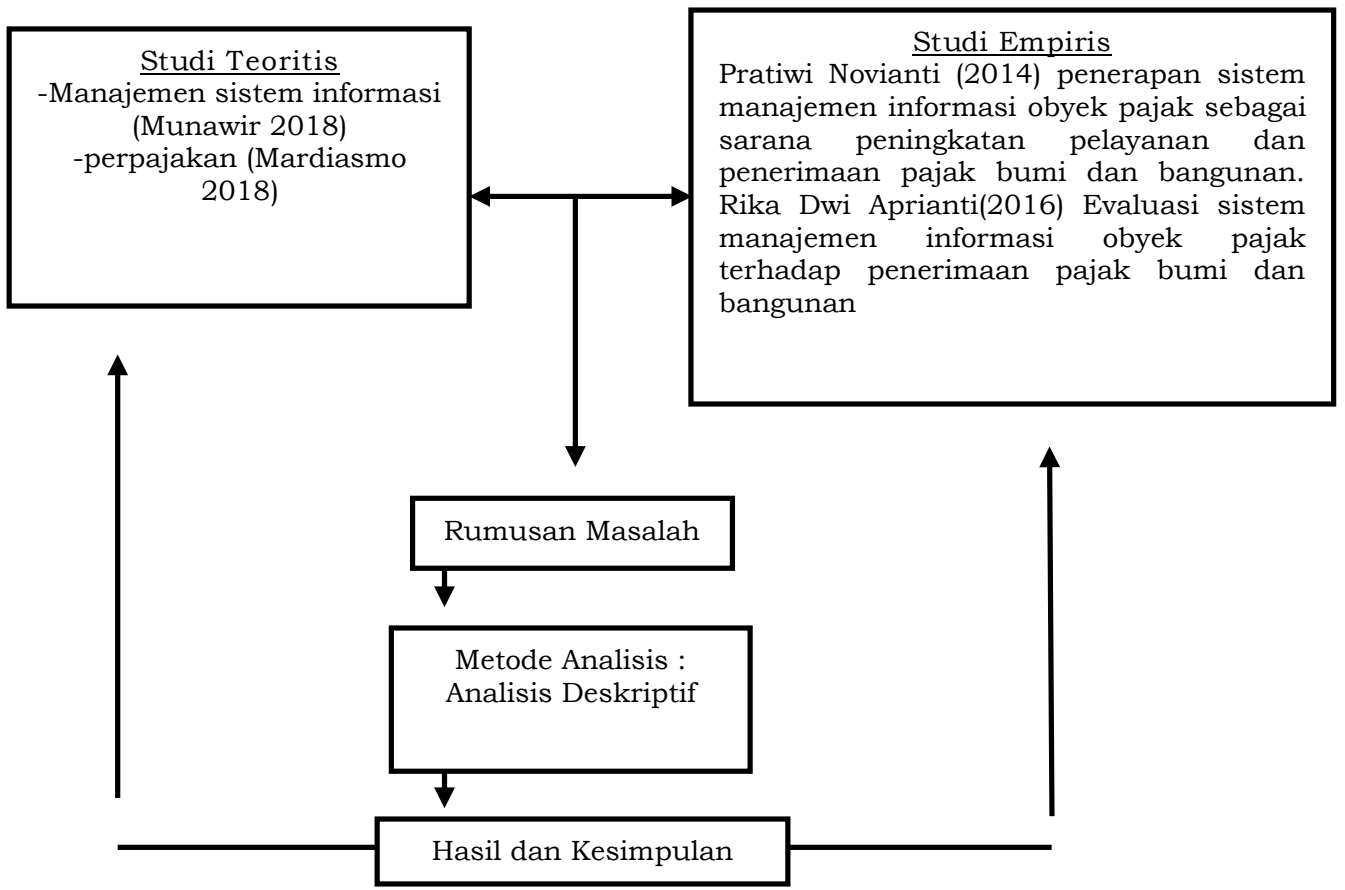

\section{METODE PENELITIAN}

Penelitian dilakukan pada Badan Pengelola Keuangan, Aset dan Pendapatan Daerah (BPKAPD) Kota Baubau yang beralamat di Jalan Raya Palagimata Kel, Lipu. Kec, Betoambari Kota Baubau, Sulawesi Tenggara.

Pajak.

Objek dalam penelitian ini adalah sarana PBB yaitu Sistem Manajemen Informasi Objek

Jenis data dalam penelitian ini adalah data kuantitatif dan kualitatif yaitu berupa uraian penjelasan dari objek penelitian dan juga pernyataan dalam kuesioner yang akan diklasifikasikan ke dalam kategori menggunakan skala guttman. Data kuantitatif dalam penelitian ini adalah jawaban responden atas pernyataan kuesioner yang diukur menggunakan skor dari skala guttman.

Sumber data yang digunakan adalah data primer data yang didapatkan atau dikumpulkan sendiri yakni langsung diperoleh penulis dari informan atau partisipan melalui observasi dan dokumentasi. Data sekunder adalah sumber data penelitian yang diperoleh peneliti secara tidak langsung melalui media perantara (diperoleh dan dicatat oleh pihak lain). Sumber data sekunder dalam penelitian ini berupa laporan Realisasi Anggaran (LRA) dari

Metode pengumpulan data yang digunakan adalah dokumen, wawancara, kuisioner/angket dan observasi

Jenis skala yang digunakan untuk menjawab bagian pertanyaan penelitian adalah skala guttman. Menurut Sugiyono (2017:96) "skala guttman digunakan apabila ingin mendapatkan jawaban tegas terhadap suatu permasalahan yang ditanyakan". Skala ini berisikan item dengan dua pilihan jawaban untuk dipilih responden. Umumnya berupa pernyataan ya/tidak, setuju/tidak dan sejenisnya yang berupa jawaban bersifat jelas dan konsisten. Responden yang menjawab "Ya" diberi skor 1 dan responden yang menjawab "Tidak" diberi skor 0. 
Metode analisis data yang digunakan dalam penelitian ini adalah analisis deskriptif. Analisis deskriptif memberikan gambaran mengenai variabel penelitian. Metode deskriptif dapat diartikan sebagai prosedur pemecahan masalah yang diselidiki dengan menggambarkan keadaan subjek atau objek dalam penelitian dapat berupa orang, lembaga, masyarakat dan yang lainnya yang pada saat sekarang berdasarkan fakta-fakta yang tampak atau apa adanya.

Metode ini digunakan untuk mendeskripsikan hasil evaluasi sistem manajemen informasi objek pajak (SISMIOP) sebagai sarana pelayanan penerimaan pajak bumi dan bangunan di Kota Baubau. Adapun rumus yang digunakan yaitu :

$$
P=\frac{f}{} \times 100 \%
$$

n

$$
\begin{aligned}
\text { Dimana }: \mathrm{P} & =\text { Persentase } \\
\mathrm{f} & =\text { Jumlah jawaban responden } \\
\mathrm{n} & =\text { Total skor jawaban tertinggi }
\end{aligned}
$$

(Sumber : Ridwan, 2008)

Tabel 3.1 Penentuan Kategori Rata-Rata Skor Pernyataan Responden

\begin{tabular}{|c|c|c|}
\hline No. & Persentase & Kriteria \\
\hline 1 & $90 \%-100 \%$ & Sangat Efektif \\
\hline 2 & $80 \%-89 \%$ & Efektif \\
\hline 3 & $70 \%-79 \%$ & Cukup Efektif \\
\hline 4 & $60 \%-69 \%$ & Kurang Efektif \\
\hline 5 & $<59,99 \%$ & Tidak Efektif \\
\hline
\end{tabular}

Sumber : Ridwan, 2008

\section{HASIL PENELITIAN DAN PEMBAHASAN}

\subsection{Hasil Evaluasi Deskriptif}

Berdasarkan keputusan Mentri keuangan No.1002/KMK. .04/1995 tentang pelimpahan wewenang penagihan PBB kepada Gubernur Kepala Daerah Tingkat I dan atau Walikota/Bupati kepala Daerah Tingkat II, Pemerintah Kabupaten/Kota diberi wewenang untuk memungut PBB. Di Kota Baubau tersebut kemudian di tugaskan kepada Badan Pengelola Keuangan, Aset dan Pendapatan Daerah bagian Bidang PBB sebagai kordinator pemungutan pendapatan daerah untuk melaksanakan tugas Pemungutan PBB. Tugas BPKAPD yang dilaksanakan selama meliputu membantu pendataan, perencanaan target anggaran, menyampaikan SPPT dan dokumtentasi PBB lainnya, pemungutan PBB pelaporan realisasi PBB serta pengendalian dan pengawasannya.

Tabel 4.1 Penerimaan PBB Kota Baubau

\begin{tabular}{|l|c|c|c|c|c|c|c|c|}
\hline \multirow{2}{*}{ Thn } & \multicolumn{2}{|c|}{ Pokok ketetapan } & \multicolumn{2}{c|}{$\begin{array}{c}\text { Realisasi pokok } \\
\text { ketetapan }\end{array}$} & \multirow{2}{*}{ Sisa pokok ketetapan } & \multirow{2}{*}{$\%$} \\
\cline { 2 - 5 } & SPPT & JMLH (Rp) & SPPT & JMLH (Rp) & & SPPT & JML H(Rp) & \\
\hline 2013 & 44.789 & 3.117 .900 .000 & 25.766 & 1.718 .133 .000 & 55.6 & 19.023 & 1.459 .767 .000 & 39,29 \\
\hline 2014 & 41.539 & 3.039 .037 .977 & 22.805 & 1.964 .075 .905 & 64.6 & 18.734 & 1.074 .962 .072 & 35.4 \\
\hline 2015 & 42.122 & 4.502 .930 .476 & 23.713 & 2.896 .656 .647 & 64.3 & 18.409 & 1.607 .273 .829 & 35.7 \\
\hline 2016 & 43.205 & 4.683 .504 .014 & 23.585 & 3.033 .448 .839 & 64.8 & 19.620 & 1.650 .055 .175 & 35.2 \\
\hline 2017 & 44.025 & 4.990 .883 .144 & 23.977 & 3.098 .225 .766 & 62.1 & 20.048 & 1.892 .657 .378 & 37.9 \\
\hline 2018 & 45.165 & 5.076 .704 .953 & 24.920 & 3.295 .280 .179 & 64.9 & 20.245 & 1.781 .424 .774 & 35.1 \\
\hline
\end{tabular}


Berdasarkan pada tabel 4.2 bahwa jumlah objek 2013 dapat dilhat pada pokok ketetapan (SPPT) sebanyak 44.789 yang terealisasi sebesar 25.766 dengan jumlah penerimaan sebesar Rp.1.718.133.000 dari KPP Pratama Baubau. Pada tahun 2014 penerimaan pajak bumi dan bangunan mengalami peralihan dari kpp pratama Baubau ke PEMDA dengan menggunakan SISMIOP. Pada tahun 2014 pokok ketetapan (SPPT) sebanyak 41.539 yang terealisasi sebanyak 22.805 dengan jumlah penerimaan sebesar Rp.1.964.075.905. pada tahun 2015 pokok ketetapan (SPPT) meningkat sebanyak 42.122 yang terealisasi sebanyak 23.713 dengan penerimaan sebesar Rp. 2.896.656.647. kemudian, di tahun 2016 pokok ketetapan (SPPT) sebanyak 43.205 yang terealisasi sebanyak 23.585 dengan penerimaan sebesar Rp. 3.033.448.389. tahun 2017 pokok ketetapan (SPPT) sebanyak 44.025 yang terealisasi sebanyak 23.977 dengan jumlah penerimaan sebesar Rp. 3.098.225.766. tahun 2018 pokok ketetapan (SPPT) sebanyak 45.165 yang terealisasi sebanyak 24.920 dengan jumlah penerimaan sebesar Rp.3.295.280.178.

\subsection{Sistem Manajemen Informasi Objek Pajak}

Kegiatan utama SISMIOP terdiri dari:

1. Pendataan

Pendataan pada Bidang PBB di BPKAPD terlebih dahulu di awali dengan mengisi SPOP (Surat Pemberitahuan objek pajak) yang kemudian akan diteliti oleh pegawai PBB untuk memastikan bahwa SPOP telah diisi dengan benar dan jelas juga untuk memastikan posisi relative dari objek pajak sehingga pada saat pemberian NOP akan lebih dimudahkan.

Bidang PBB akan melakukan penomoran formulir yang berfungsi sebagai kode nomor identitas dari SPOP supaya memudahkan pihak pegawai PBB ketika menyimpan dan melakukan pencarian kembali, selanjutnya melakukan perekaman SPOP untuk memastikan dan menyimpan data objek dan subjek pajak kedalam basis data dengan menggunakan bantuan komputer dan akan melakukan pengawasan data untuk mevalidasi data hasil perekaman guna memastikan kebenaran dan kelengkapannya.

2. Penilaian

Objek pajak yang akan dimulai yaitu OP bumi (permukaan tanah,tubuh bumi misalnya sektor pertambangan migas dan hasil produksi) dan OP bangunan (bangunan yang terbagi menjadi dua yakni penilaian massal dan penilaian individu. Cara penilaian yang dilakukan untuk penilaian massal dilakukan dengan secara sistematis untuk sejumlah OP pada saat tertentu secara bersamaan yang menggunakan prosedur standar dengan menggunakan program aplikasi SISMIOP (CAV). Penilaian individu dilakukan dengan memperhitungkan semua karakteristik dari setia OP dilakukan terhadap OP standar, OP nostandar, OP khusus dan OP bernilai tinggi.

3. Penetapan

Ada beberapa kegiatan yang akan dilakukan pada proses penetapan:

a. Penerbitan SPPT

Penerbitan SPPT yang dilakukan BPKAPD bidang PBB berdasarkan SPOP (surat pemberitahuan objek pajak) orang atau badan yang terdaftar sebagai subjek pajak/wajib pajak serta mendaftarkan tanah-tanah dan atau bangunan yang dimiliki, dikuasai atau dimanfaatkannya.

b. Pencetakan massal

Cetak massal menggunakan sistem untuk dapat mengeluarkan SPPT sampai sekarang. Sebelum cetak massal Bidang PBB akan terlebih dahulu melakukan pemutakhiran data agar data yang akan dicetak massal semua sesuai dengan data yang sebenarnya. Seja PBB yang mulanya adalah pajak pusat kemudian dialihkan menjadi pajak daerah daerah. 
Tabel 4.2 rincian jumlah SPPT dan Pokok PBB per kecamatan tahun 2017

\begin{tabular}{|c|c|c|c|c|}
\hline \multirow{2}{*}{ No } & \multirow{2}{*}{ kecamatan } & \multirow{2}{*}{$\begin{array}{c}\text { Jumlah } \\
\text { kelurahan }\end{array}$} & & \multicolumn{2}{|c|}{ Pokok ketetapan } \\
\cline { 4 - 5 } & & 7 & 11.776 & 1.736 .477 .594 \\
\hline 1 & Wolio & 5 & 7.374 & 1.052 .004 .494 \\
\hline 2 & Betoambari & 4 & 2.555 & 69.745 .436 \\
\hline 3 & Sorawolio & 5 & 3.646 & 183.893 .156 \\
\hline 4 & Bungi & 5 & 5.160 & 328.541 .582 \\
\hline 5 & Kokalukuna & 6 & 5.147 & 702.569 .719 \\
\hline 6 & Murhum & 5 & 5.190 & 819.073 .387 \\
\hline 7 & Batu poaro & 6 & 3.177 & 98.577 .776 \\
\hline 8 & Lea-lea & 5 & $\mathbf{4 4 . 0 2 5}$ & $\mathbf{4 . 9 9 0 . 8 8 3 . 1 4 4}$ \\
\hline & Jumlah & $\mathbf{4 3}$ & & \\
\hline
\end{tabular}

Sumber Data: BPKAPD, Bidang PBB

Tabel 4.4 rincian jumlah SPPT dan pokok PBB per kecamatan tahun 2018

\begin{tabular}{|c|c|c|c|c|}
\hline No & kecamatan & \multirow{2}{*}{$\begin{array}{c}\text { Jumlah } \\
\text { kelurahan }\end{array}$} & & \multicolumn{2}{|c|}{ Pokok ketetapan } \\
\cline { 4 - 5 } & & 7 & 11.753 & 1.732 .909 .427 \\
\hline 1 & Wolio & 5 & 7.533 & 1.071 .751 .790 \\
\hline 2 & Betoambari & 4 & 3.037 & 109.373 .031 \\
\hline 3 & Sorawolio & 5.900 & 203.218 .716 \\
\hline 4 & Bungi & 5 & 3.950 .420 \\
\hline 5 & Kokalukuna & 6 & 5.154 & 33.850 .42 \\
\hline 6 & Murhum & 5 & 5.184 & 685.450 .602 \\
\hline 7 & Batu poaro & 6 & 5.197 & 812.395 .262 \\
\hline 8 & Lea-lea & 5 & 3.407 & 127.755 .705 \\
\hline & Jumlah & $\mathbf{4 3}$ & $\mathbf{4 4 . 0 2 5}$ & $\mathbf{5 . 0 6 7 . 7 0 4 . 9 5 3}$ \\
\hline
\end{tabular}

Sumber Data: BPKAPD, Bidang PBB

Tabel 4.3 tahun 2017 terdapat jumlah wajib pajak sebesar 44.025 jumlah SPPT dengan pokok pajak sebesar Rp. 4.990.883.144 sedangkan tabel 4.4 tahun 2018 jumlah wajib pajak meningkat menjadi 45.165 jumlah SPPT dengan pokok pajak sebesar Rp. 5.076.704.953 . terdapat peningkatan jumlah wajib pajak sebanyak 1417 jumlah SPPT dan jumlah pokok pajak dari tahun 2017 ke 2018 terjadi peningkatan sebanyak 1.463.892.499.

c. Penyerahan SPPT

Penyerahan SPPT, STTS maupun DHKP pihak BPKAPD yang telah dicetak, dirobek/disusun, dibundel per desa, kemudian dibuat berita acara untuk diserahkan ke camat dan lurah. Penyerahan SPPT dan DHKP dari Walikota ke camat dan lurah dalam suatu rapat akbar yang di hadiri oleh semua camat dan lurah serta instansi yang terkait untuk tahun 2017 dilaksanakan pada awal bulan maret 2017. Untuk tahun 2018 dilaksanakan pada awal bulan maret 2015.

4. Pelayanan satu tempat

Beberapa pelayanan yang dilakukan Bidang PBB Kota Baubau sebagai berikut:
a. Pendaftaran objek pajak baru
b. Mutasi
c. Salinan SPPT
d. Keberatan atas pajak terhutang
e. Pengurangan pajak bumi dan bangunan
f. Pembetulan dan pembatalan SPPT/SKP/STP PBB 
g. Penundaan jatuh tempo

h. Kompensasi dan restitusi

Tabel 4.5 Rincian Jumlah SK Permohonan Pelayanan Tahun 2017 dan 2018

\begin{tabular}{|l|l|c|c|}
\hline No & \multicolumn{1}{|c|}{ Jenis pelayanan } & $\begin{array}{c}\text { SK yang terbit } \\
\text { tahun 2017 }\end{array}$ & $\begin{array}{c}\text { SK yang terbit } \\
\text { tahun 2018 }\end{array}$ \\
\hline 1 & Pendaftaran objek pajak baru & - & - \\
\hline 2 & Mutasi & 152 & 52 \\
\hline 3 & Salinan SPPT & - & - \\
\hline 4 & Keberatan atas pajak terutang & 3 & - \\
\hline 5 & Pengurangan PBB & 6 & 13 \\
\hline 6 & Pembetulan & 42 & 42 \\
& Pembatalan & 36 & 18 \\
& SPPT/SKP/STPPBB & & - \\
\hline 7 & Penundaan jatuh tempo & - & - \\
\hline 8 & Kompensasi dan restitusi & - & \\
\hline
\end{tabular}

Sumber data: BPKAPD, Bidang PBB Kota Baubau

Tabel 4.5 terdapat beberapa permohonan yang dilakukan oleh wajib pajak dalam tahun 2017 dan 2018. Tahun 2017 terdapat permohonan mutasi 153, keberatan 3, pengurangan 6, pembetulan 42, pembatalan 36 sedangkan pada tahun 2015 terjadi penurunan permohonan yang dilakukan oleh wajib pajak diamana mutasi 52, keberatan tidak ada, pengurangan 13, pembetulan 42 dan pembatalan 18 .

5. Pembayaran dan penagihan

Tata cara pembayaran tidak dilakukan di kanto BPKAPD bidang PBB melainkan dilakukan dengan cara wajib pajak langsung membayar di Bank sultra denga membawa SPPT seperti pada penyetoran biasa.

\subsection{Evaluasi Sistem Manajemen Informasi Objek Pajak Sebagai Sarana Pelayanan} Penerimaan PBB Kota Baubau

Evaluasi Sistem Manajemen Informasi Objek Pajak (SISMIOP) sebagai sarana pelayanan Penerimaan Pajak Bumi dan Bangunan:

1. Pendataan dilaksanakan berdasarkan keputusan Direktorat jendra Pajak Nomor KEP533/PJ/2000. Berdasarkan dari pernyataan diatas bahwa pendataan objek pajak yang dilakukan pada BPKAPD bidang PBB telah terlaksana dengan cukup baik dan memadai karena sudah dapat mengakomodir semua proses pelayanan PBB yang ada mulai dari pendataan dengan menggunakan SPOP dan LSPOP, pemberian identitas objek pajak (nomor objek pajak) perekaman data dan pemeliharaan basis dat.

2. Penilaian dilaksanakan dalam Sistem Manajemen Informasi Objek Pajak dimana pegawai pajak melakukan penilaian di lapangan atau tempat tersebut sebelum di masukan ke sistem dan dilakukan penilaian individu. Dimana penilaian individu terbagi menjadi 2 yaitu untuk penilaian objek pajak yang bersifat non standard dan khusus. Dimana non standar objekobjek pajak yang memenuhi salah satu dari kriteria luas tanah $>10.000 \mathrm{~m} 2$, luas bangunan $>1.000 \mathrm{~m} 2$ dan jumlah lantai >4 lantai sedangkan objek PBB khusus seperti: pelabuhan laut,pelabuhan udara,pompa bensin. dan penilaian massal Bumi dan bangunan dilakukan oleh OC guna menghitung NJOP bumi dan bangunan secara massal untuk seluruh OP dalam 1 wilayah desa/kelurahan. Berdasarkan pernyataan di atas bahwa penilaian objek pajak yang dilakukan pada BPKAPD bidang PBB kurang baik karena jika dilihat pada keputusan DJP nomor 04/PJ.6/2000 tentang pelaksanaan penilaian DJP melakukan penilaian setahun sekali sedangkan pada BPKADP bidang PBB melakukan penilaian 3 tahun sekali. 
3. Pelaksanaan penetapan pada Sistem Manajemen Informasi Objek Pajak, berdasarkan pernyataan di atas bahwa penetapan yang dilakukan BPKAPD bidang PBB sudah berjalan cukup baik dikarenakan dalam penetapan PBB yang kemudian dilakukan penerbitan massal , pencetakan massal, berupa SPPT, STTS, DHKP dan sejenisnya. penyerahan SPPT kemudian dilakukan rapat evaluasi untuk penyerahan ke lurah sudah dilakukan sesuai prosedur PBB sampai pada sistem.

4. Pelaksanaan Pelayanan Satu Tempat pada Sistem Manajemen Informasi Objek Pajak sudah termasuk cukup baik dimana segi pelayanan yang dilakukan BPKAPD bidang PBB kepada wajib pajak dari tahun ke tahun lebih meningkat menjadi baik dilihat dari tahun 2017 sampai tahun 2018 pelayanan yang dilakukan oleh Bidang PBB ke wajib pajak mulai dari mutasi, keberatan, pengurangan, pembetulan dan pembatalan terjadi penurunan permohonan. Dengan penurunan surat permohonan yang dilakukan wajib pajak maka dapat dilihat dari tahun ke tahun manfaat akan SISMIOP lebih memberikan dampak yang baik dan menunjukan pelaksanaan SISMIOP yang dilakukan Bidang PBB telah baik sehingga yang mengajukan permohonan semakin berkurang.

Pelaksanaan Pembayaran dan Penagihan pada Sistem Manajemen Informasi Objek Pajak termasuk kriteria cukup baik dikarenakan pembayara tidak dilakukan di kantor BPKAPD Bidang PBB melainkan dilakukan dengan cara wajib pajak pajak langsung membayar di Bank Sultra dengan membawa SPPT.

\subsection{Kesimpulan}

\section{KESIMPULAN DAN SARAN}

Berdasarkan hasil penelitian dan pembahasan yang telah di uraikan dapat ditarik kesimpulan bahwa pelaksanaan Sistem Manajemen Informasi Objek Pajak (SISMIOP) yang merupakan suatu system yang digunakan oleh Badan Pengelolaan Keuangan, Aset dan Pendapatan Daerah bagian Bidang Pajak Bumi dan Bangunan (PBB) telah terlaksana dengan cukup baik. Pelaksanaan SISMIOP sudah terlaksana dengan baik dapat dilihat dari system yang dapat mengakomodir atau menjalankan seluruh proses alur PBB yang ada, yang tentunya harus di dukung dengan peralatan yang memadai, tenaga kerja yang berkopenten serta adanya kepatuhan dan kedisiplinan dari pengguna.

\subsection{Saran}

Penelitian ini dimasa mendatang diharapkan dapat menyajikan hasil penelitian yang berkualitas lagi dengan adanya beberapa masukan mengenai beberapa hal di antaranya:

1. Untuk penelitian mendatang, disarankan survey dengan metode lain, misalnya wawancara secara langsung agar dapat dilakukan pengawasan atas jawaban responden dalam menjawab pertanyaan.

2. Untuk penelitian mendatang, dapat memperluas wilayah sampel penelitian dengan memasukan wajib pajak sebagai sampling di area sekitar wilayah Kota Baubau.

3. Lebih memperbanyak tempat-tempat pembayaran/Bank yang ditunjuk untuk menerima pembayaran PBB di Kota Baubau.

4. Sebaiknya pemerintah Kota Baubau lebih rutin dan meningkatkan sosialisasi kepada masyarakat mengenai perpajakan dan peraturan-peraturan yang terkait agar masyarakat Kota Baubau lebih mengetahui betapa pentingnya membayar pajak sehingga kesadaran wajib pajak lebih meningkat. 
Jurnal Akuntansi dan Keuangan Volume V/1/Februari 2020

ISSN (Online) : 2503-1635, ISSN (Print): 2088-4656

\section{DAFTAR PUSTAKA}

Amsyah, Zulkifli.2005.Manajemen Sistem Informasi.Jakarta: PT SUN.

Ardananto, Bagiyo, "Profesionalisme Aparat Pajak dalam Memberikan Pelayanan Restitusi PPN dan Pengaruhnya terhadap Kepatuhan Wajib Pajak”,Tesis S2 Program Pasca Sarjana Fakultas Ilmu Sosial dan Ilmu Politik Universitas Indoensia, 2003

Boediono, B, "Pelayanan Prima Perpajakan", Rineka Cipta, Jakarta, 2007. Brotodihardjo, Santoso R, "Pengantar Ilmu Hukum Pajak cetakan ke IX”, Eresco, Bandung, 1989.

Direktorat Jenderal Pajak, "Layanan Informasi Pajak Bumi dan Bangunan" Direktorat Jenderal Pajak, Jakarta, 2008.

Dessler, Gary, 2006. Manajemen Sumber Daya Manusia. Edisi ke sepuluh. PT Intan sejati. Klaten

Echols, J. dan Shadily, Hasan, 1996. Kamus Bahasa Inggris Indonesia. PT Gramedia, Jakarta Furtwengler, Dale,"Penilaian Kinerja”, Andi offset, Yogyakarta, 2002.

George H. Bodnar, William S. Hopwood.2000. Sistem Informasi Akuntansi, Buku Satu,Jakarta:Salemba Empat,

Gronroos, Michael, 1990. Perceived Service Quality Model. Published OhioUniversity Press, California.

Indriantoro dan Supomo. 2009. Metodologi Penelitian Bisnis Untuk Akuntansi dan Manajemen.Edisi Revisi.BPFE, Yogyakarta.

Jogiyanto HM.1999.Analisis dan Disain Informasi:Pendekatan Terstruktur Teori dan Praktek Aplikasi Bisnis, Offset, Yogyakarta

Keputusan Direktur Jenderal Pajak Nomor Kep -115/Pj./2002 Tentang Perubahan Atas Keputusan Direktur Jenderal Pajak Nomor : Kep-533/Pj/2000 Tentang Petunjuk Pelaksanaan Pendaftaran, Pendataan Dan Penilaian Objek Dan Subjek Pajak Bumi Dan Bangunan (PBB) Dalam Rangka Pembentukan Dan Atau Pemeliharaan Basis Data Sistem Manajemen Informasi Objek Pajak (SISMIOP)

Krismaji. 2015. Sistem informasi akuntansi.Edisi ke Empat, SEKOLAH TINGGI ILMU MANAJEM YKPN, Yogyakarta 2015

Kotler, Philip. 2002. Manajemen Pemasaran Di Indonesia : Analisis, Perencanaan, Implementasi Dan Pengendalian. Jakarta:Salemba Empat.

Mardiasmo, Perpajakan edisi terbaru 2018,Andi, Yogyakarta, 2018

Mcleod, Raymond, 2012, Sistem Informasi Manajemen, Jakarta: salemba Empat, 2012

Moenir, H.A.S., 2020 ,Manajemen Pelayanan Umum di Indonesia, Bumi Aksara,Jakarta.

Mutia, I, "Konsep Sistem Informasi Manajemen", Fakultas Ekonomi USU, 2004. Nasution, Darmin, "Pemilik NPWP mencapai 10,8 Juta", Seputar Indonesia, 19Januari 2019.

Nugroho, Eko, "Sistem Informasi Manajemen Konsep, Aplikasi dan Perkembangannya", Andi Offset, Yogyakarta, 2008.

Pemerintah Republik Indonesia. 2007. Undang-Undang Nomor 28 Tahun 2007 tentang Ketentuan Umum Dan Tata Cara Perpajakan. Jakarta.

Sayaketi, Siwi.2010. Pengaruh Aplikasi Sistem Manajemen Informasi Objek Pajak (SISMIOP) Tehadap Kinerja Aparatur Pajak. Skripsi. Universitas Islam Negeri Syarif Hidayatullah. Jakarta.repository.uinjkt.ac.id/dspace/bitstream/ 123456789/21542/1/SIWI SAYAKETIFEB.pdf. Diakses 22 April 2019 . Hal. 1

SE-60/DJP/2001“Petunjuk Pelaksanaan, Pendaftaran, Pendataan dan Penilaian Objek dan Subjek Pajak Pajak Bumi dan Bangunan dalam Rangka Pembentukan dan atau Pemeliharaan Basis Data Sistem Manajemen Informasi Objek Pajak SISMIOP)", Direktorat Jenderal Pajak, Jakarta, 2001. 
Jurnal Akuntansi dan Keuangan Volume V/1/Februari 2020

ISSN (Online) : 2503-1635, ISSN (Print): 2088-4656

Siregar, Sofyan. 2013. Metode Penelitian Kuantitatif: Dilengkapi Perbandingan Perhitungan Manual \& SPSS Edisi Pertama. Jakarta: PRENADAMEDIA GROUP.

Sinambela. 2006. Reformasi Pelayanan Publik . Jakarta; Bumi Aksara.

Sugiyono. 2015. Statistika Untuk Penelitian. Bandung: CV. ALFABETA.

Sugiyono, "Metode penelitian Bisnis", CV Alfabeta, Bandung, 2005.

Supranto,1997.Pengukuran Tingkat Kepuasan: Untuk Menaikkan Pangsa Pasar,Rineka Cipta, Jakarta

Tata Sutabri,2005.Sistem Informasi Manajemen.Yogyakarta

Tambunan, Tulus, "Perekonomian Indonesia Beberapa Masalah Penting, Ghalia Indonesia", Jakarta, 2003

http://www.djpk.kemenkeu.go.id/wp-content/uploads/2018/08/pajak_daerah-1.pdf

https://www.online-pajak.com/pajak-daerah 